\title{
Antonio León Pinelo (1594-1660) Primer apologista de la Selva peruana
}

\author{
Luis Hernán Ramírez*
}

Antonio León Pinelo, el primer bibliógrafo del derecho indiano, es también el primer apologista de la selva tropical peruana y sudamericana en su crónica tardía, El Paraíso en el Nuevo Mundo, escrita en 1656 pero inédita hasta 1943 en que la publicó Raúl Porras Barrenechea con motivo de la celebración del IV Centenario del Descubrimiento del río Amazonas'.

Antonio León Pinelo fue bijo del Capitân Diego López de León quien a causa de su origen judío-portugués y temeroso de la Inquisición que había decretado persecución contra los de su raza huyó de Lisboa a España y se asentó en Valladolid donde debió nacer su hijo Antonio hacia 1594 según indagaciones de Guillermo Lohmann Villena ${ }^{2}$. Siempre huyendo de la Inquisición el Capitán Diego López se trasladó con su familia al Nuevo Mundo y se estableció primero en Buenos Aires y después en Córdoba. Desde aquí envió a su hijo Antonio a estudiar en Lima en 1612.

Antonio León Pinelo, en Lima, estuvo en el Colegio Sanmartiniano e hizo estudios de derecho en la Universidad de San Marcos. En 1617 se graduó de Bachiller y al año siguiente de doctor y abogado. En el año de 1618 publicó su primer libro Poema a la Inmaculada Concepción de la Virgen. Fue nombrado alcalde Mayor de Minas en Oruro y Potosí. De aquí

* Ponencia leída en el I Coloquio Cronistas del Perú, Homenaje a Raúl Porras Barrenechea, en el Instituto Riva-Agüero, el 20 de marzo de 1997. Coloquio organizado por el Instituto Raúl Porras Barrenechea, el Instituto Riva-Agüero y la Asamblea Amistosa Literaria, capítulo del Perú.

1 Sobre la historia y odisea del manuscrito, que en alguna oportunidad estuvo en manos del erudito peruano Eusebio Llano Zapata, ver Raúl Porras Barrenechea. Prólogo, en Antonio León Pinelo. El Paraíso en el Nuevo Mundo. Comité del IV Centenario del Descubrimiento del río Amazonas, 1943, t.I, pp. XXIII-XXVII.

2 Guillermo Lohman Villena. Prólogo, en Antonio León Pinelo, El gran canciller de las Indias, Sevilla, 1955, p. 27. 
se encaminó a Tucumán por la vía de Tarija y se embarcó para España en el puerto de Buenos Aires.

Desde su llegada a España (1622) se avecindó en Madrid, revalidó su título de abogado para realizar actividades forences en la metrópoli y en 1629 obtuvo una plaza de Relator en el Consejo Superior de las Indias. En el año de 1631 salió en defensa de la Universidad de San Marcos en un polémico opúsculo que tituló Por la Real Universidad y Escuelas Generales de San Marcos.

Como poeta León Pinelo participó, junto con otros ingenios de su tiempo, en el libro-homenaje Fama a la vida y muerte de Lope Félix de Vega y Carpio (Madrid, 1636) con un soneto elegíaco que llora la muerte del poeta y un largo poema panegírico titulado Félix Mantuano. En 1641, Antonio León Pinelo fue nombrado Relator Supremo de la Cámara y más tarde ascendió a Oidor de la Casa de Contratación de Sevilla. En 1658 se le extendió el título de Cronista Mayor de Indias y dejo de existir en Madrid en 1660.

Antonio León Pinelo tuvo siempre al Perú como su segunda patria y mantuvo de la ciudad de Lima una apasionada nostalgia que vertió en numerosas páginas de su copiosa obra édita e inédita ${ }^{3}$. En 1629 publicó en Madrid una primerà obrạtepresentativa de sur vasta erudición, Epitome de la Biblioteca Orientak Eecidental ji Geografias presentada por el propio autor como "primicia de sus largos estudios".

Como jurista dejó dos trabajos: Confirmaciones Reales, publicado en Madrid en 1630 y El Gran Canciller de las Indias, póstumamente editado, en 1955, con un estudio de Guillermo Lohmana Villena ${ }^{4}$. Como historiador dedicó a Lima y a su insigne ayuntamiento Antigüedades de Lima (1631) con la historia de la fundación de esta ciudad y su grandeza. También escribió: La vida de Santo Toribio, Arzobispo de lima (1653), Aparato político de las Indias Occidentales (1653) y Los anales de la historia de Madrid desde el nacimiento de Nuestro Señor Jesucisto (1658). Entre su vasta producción hay dos libros curiosos: Sobre si el chocolate quebranta

3 Sobre la obra de Antono León Pinelo ver: Raúl Porras Barrenechea, op. cit., t. I, pp. III-XLV.

4 Antonio León Pinelo, El gran canciller de las Indias. Sevilla, Escuela de Estudios Hispano-Americanos, 1955. 
el ayuno eclesiástico (1636). Curioso no sólo por el título sino porque en él se informa de 120 clases de bebidas que se preparan y toman en las Indias, y Velos antiguos y modernos en los rostros de las mujeres (1641) en el que hace una alusión a las "tapadas" limeñas.

En las páginas del El Paraíso en el Nuevo Mundo, Antonio León Pinelo, manejando prodigicamente la imaginación y la erudición hizo el mejor elogio y alabanza de la Amazonia Peruana al sustentar la original y extravagante tesis de ubicar en esta ubérrima región de nuestra patria el bíblico paraíso terrenal. Haciendo gala de una vasta erudición teológica, bíblica, histórica y geográfica, León Pinelo sostiene y "demuestra" que la inicial morada de nuestros primeros padres estuvo en el centro de las Indias, en América del Sur que por algo tiene la forma de un corazón. Dentro de este continente el autor ubica al Paraíso en la selva amazónica, en un círculo imaginario de nueve grados de diámetro que son 160 leguas y 460 de circunferencia.

Una de las razones que mueven a León Pinelo a dar esta ubicación del Paraíso es que en el centro de nuestro continente, en la selva amazónica, se originan los cuatro ríos mayores que en el orbe se conocen: el Río de la Plata, el Amazonas, el Orinoco y el Magdalena a los que identifica con los cuatro ríos de la Sagråda e̊scritura:Phisón, Gehón. Perath a Hidekel respectivamentes.

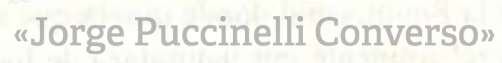

La zona señalada para el Paraíso en el Nuevo Mundo está custodiada por la cadena de volcanes andinos que en la fantasía y la argumentación de León Pinelo representa al ángel de la espada de fuego que Dios puso en la entrada del Paraíso para impedir el retorno de la pareja que cayó en pecado. En un largo capítulo, León Pinelo deja entender claramente que "la defensa del Paraíso fue un vallado de fuego o una muralla de volcanes que con el horror de los truenos, el furor de las piedras y el ardor de las llamas que causan, arrojan y brotan, estorbasen a Adán el volver al sitio que por su culpa perdio"'. Los volcanes andinos: Cozalla, Cozapilla, Ubinas, Misti, Sabancaya, Cotopaxi, Sangay, Pichincha son la flamífera espada con que Dios interdictó el Paraíso en el Nuevo Mundo.

5 Antonio León Pinelo, El Paraíso, ed. cit., t. I, pp. 138-140.

6 Antonio León Pinelo, op., cit, t. I, pp. 334-351. 
Como un argumento más de su original tesis sobre el Paraíso en el Nuevo Mundo, León Pinelo sostiene que el bíblico árbol del bien y de mal fue la granadilla, maravillosa fruta de la selva amazónica que por su color, olor y sabor fue capaz de engolosinar a Eva. La flor de la granadilla ofrece a la vista los signos de la Pasión de Cristo: lanza, esponja, escalera, cruz y corona de espinas, como una demostración divina de que en la misma fruta del pecado se ofrece la flor con las señales del perdón ${ }^{7}$.

La singular y peregrina tesis de León Pinelo va más allá de lo sospechado en sus proposiciones teológicas. El origen de las razas humanas está en América del Sur. El hombre nació en nuestro país y con Noé y su arca pasó desde la costa central del Perú hasta el continente asiático. Según las conclusiones teológicas de nuestro autor, Noé construyó su arca en los aledaños de Lima con madera de la selva amazónica. Nueva días después del diluvio el arca comenzó a navegar sin descansar en dirección occidental. Se inclinó hacia el Norte, entró al centro de Asia y encalló en el monto Ararat. Más tarde, propagada la nueya especie humana, regresó a América por el estrecho de Bhering 8 .

Argumentado la validez de su tesis, Antonio León Pinelo hizo uno de los mejores elogios escritos a la región tropical de la selva amazónica.

Es el sitio de la Equinoccial donde quiera que se considere el más calificado y preheminente por naturaleza de todos los del Mundo. En el no se mudan los tiempos, son siempre iguales los días y las noches, ellas con la frescura que basta, ellos con el calor que conserba el perpetuo verdor de las Plantas, en continua hermosura los Campos, sin que el frio los marchite ni el rigor los agoste. Antes en eterno Verano y nunca acabada Primavera son Retratos todo el año del Terrenal Paraíso: que sin milagro ni cuidado especial de la divina Providencia con solo fiar la cultura de las Arboles al tiempo, lo aromático de las Flores al Ayre, lo útil de los Frutos a la Tierra, pudo en aquella mediante las repetidas aguas y suaves vientos que la fertilizan y tiemplan lo ardiente del Sol para que no abrase, permanecer ameno largos años, y conserbarse deleitoso prolijas edades. ¿Que

7 Antonio León Pinelo, op. cit., t. II, pp. 201-215.

8 Antonio León Pinelo, op. cit., t.I, cap. VIII, p. 38. 
lugar mas propio para el Paraíso que donde la hermosura, la amenidad, el temple y los tiempos son siempre unos y siempre buenos? Donde en los Arboles concurren Flores y Frutos cayendo las hojas viejas y caducas quando ya las nuenas y tiernas bisten los troncos despojandose los Prados de su hermosura sin perderla? Pues quando la hierba mas por la duración que por el tiempo se agosta para su multiplico, ya la que le sucede se halla tan crecida que ni se conoce la que muere ni sabe la que nace. Y si al Paraíso celeste por alabarle a nuestro modo y con lo que más nos agrada le llamamos eterno Verano, y perpetua Primavera; y esto tenía el Terrenal como sienten todos los Expositores, en la Equinoccial había de estar para que lo que es Metáfora en el del Cielo fuese verdad en el de la Tierra, con que se reconoce ser esta opinión tan fundada y probable que ninguna de las demás la abentaja ni la iguala. Y asi no sólo merece ser admitida, sino aprobada para el intento de este Cometario?.

El contenido del libro es sumamente interesante, el autor con la osada y extraña idea de querer probar que la residencia de la primera pareja de la creación divina estuvo en el Nuevo Mundo hace una extensa descripción de todas sus bellezas y maravillas naturales y dando cuenta de la producción de tan fértil región enumera y estudia sus plantas, animales y riquezas minerales; habla de tos antiguos peruanes pobladores de la selva y traza detalladamente la geografía del Perú.

En este libro Antonio León Pinelo conjuga su formación erudita y tecnológica con su gran pasión americana y peruana. Su aventurada tesis de la existencia real del paraíso terrenal en el Nuevo Mundo, aparte de su actitud fantasiosa y poética y de sus originales fundamentaciones y argumentos bíblicos y teológicos es una manifestación de que las virtudes y excelencias del mundo están potencialmente contenidas en América. El paisaje, el clima, sus recursos para aposentar físicamente la obra maestra de Dios: el paraíso terrenal ${ }^{10}$.

9 Antonio León Pinelo, op. cit., t.I, cap. VIII, p. 38.

10 Como es sabido fue Cristóbal Colón el primero que imaginó y situó el paraiso en América, en la península de Paris, en Venezuela, durante el tercer viaje en 1498. Resparece la idea en el Padre Eusebio Niremerg, el fray Pedro Simón y antes Cieza de León quien remite a las Etimologías de San Isidoro. Ver las biografías de Cristóbal, también Mitos y utopías del Descubrimiento por Juan Gil, Alianza Editorial, 3 tomos. 